\title{
MECANUM WHEELED MOBILE ROBOT FOR WELDING PROCESS
}

\author{
B. MEENAKSHIPRIYA ${ }^{1}$, R. ANILKUMAR CHOUDARY ${ }^{2}$, S. DEVA SURYA ${ }^{3}$, \\ N. SUBHASHREE ${ }^{4} \&$ A. PRENITHA \\ ${ }^{1}$ Professor, Mechatronics Engineering, Kongu Engineering College, Perundurai, Tamil Nadu, India \\ ${ }^{2,3,4,5}$ UG Student, Mechatronics Engineering, Kongu Engineering College, Perundurai, Tamil Nadu, India
}

\begin{abstract}
Welding is a sculptural process which joins the metals by fusion process. It is a permanent metal joining process and is being used in most of the industries to join the metals. The need for the autonomous welding tasks is increasing rapidly to improve the productivity. However, the robots used for this work are at a fixed location and it is moved from one working location to another by crane. Therefore the proposed work rectifies this issue by providing the moving platform for mobility of the robot. The ultrasonic sensor is employed on the mobile platform to sense the seam to be welded and simultaneously welding profile is recorded in the controller. After sensing the seam, the robot starts welding in the sensed path. For proper sensing of the seam, the groove has been provided on the workpiece. This robot is designed for the Metal Inert Gas (MIG) welding; however, it can be used for Gas welding, Arc welding and Tungsten Inert Gas (TIG) welding with little modifications.

KEYWORDS : MIG Welding, Solid Works, Mecanum Wheel \& Mobile Robot
\end{abstract}

Received: Apr 16, 2020; Accepted: May 06, 2020; Published: May 16, 2020; Paper Id.: IJMPERDJUN202052

\section{INTRODUCTION}

Welding is an essential process to build our nation in different aspects which includes agricultural products (tillers and tractors), food processing (cookers, crushers, and conveyors), mining (drills, trams and excavators), transportation (cars, trains, buses, trucks, ships and planes) security maintenance (submarines, tanks and missiles), power generation and transmission, information communication etc. [1]. Beside the common application areas of welding such as building construction, automobile manufacturing, shipbuilding and pipelines, the welding techniques are being used in more complex application fields such as nuclear reactors, aircraft and space vehicles since it provides the fastest, strongest and most economical method to join the metals. Now a day, the welding field is moved from coal-fired furnaces and hammers, which are used for forging iron, to modern techniques such as concentrated accelerated free electrons of the electron beam process. The friction welding and the laser welding process are some of the recent developments in the welding industry. Laser is used for various kinds of welding operation due to its inherent capacity in rendering precision in all types of welding works.

The essential component of today's factory is an industrial robot since it is a flexible and intelligent machines which can perform repetitive tasks with acceptable cost and quality [2]. The most commonly used robot configurations based on their kinematic structure are Cartesian coordinate robots, articulated robots, SCARA robots and Delta robots. Most of the industrial robots are programmed to carry out the specific tasks repetitively without any variation and with a high degree of accuracy. But there are some limitations with these types of robots to perform variety of task as shown in the Figure 1. As its base is fixed, the work volume is limited and cannot perform beyond its work space. Now a solution needs to be provided to overcome this issue, thus the mobile robot is introduced and 
it can perform welding process in effective manner. A single mobile robot can weld long and large work piece effectively without any restriction in its work volume. The mobility in lateral and linear direction can be achieved by employing Mecanum wheel in mobile platform. Also, the efficiency of the robot can further be improved by providing the sensor which senses the seam to be welded instead of, welding in a fixed path repetitively. Hence, the Mecanum wheeled mobile robot is proposed for welding process.

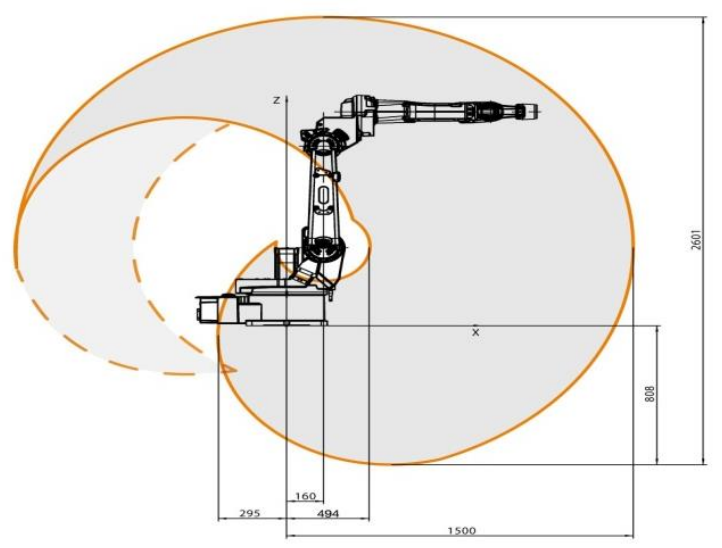

Figure 1: Limited Work volume of the Fixed Base Robot

\section{EXISTING AND PROPOSED MOBILE ROBOT FOR WELDING}

\section{- Existing Mobile Robot}

The mobile welding robot shown in Figure 2 consists of sensor, processor, controller, welding gun, two differential drives, and two passive auxiliary wheels. In addition, all the necessary electrical and control components are employed on the internal drive unit. This robot differs from its mechanical structure and driving mechanism and it has two DC servo motors which is used to actuate the main driving wheels and the other two stepper motors are used to actuate the driving crosssliders that act as a fine-tuning mechanism. The rotary motor is used to drive the welding torch which is located in front of the laser sensor to perform weld groove scanning. The passive wheels are used to prevent the robot from tipping over as it moves on a flat surface. The effect of auxiliary wheel motion to the complete system has been neglected by [3]. The drawbacks are the horizontal movement of the arm is limited to the length of lead screw and the sensor is located near the welding torch, so there are chances of it to get damaged.

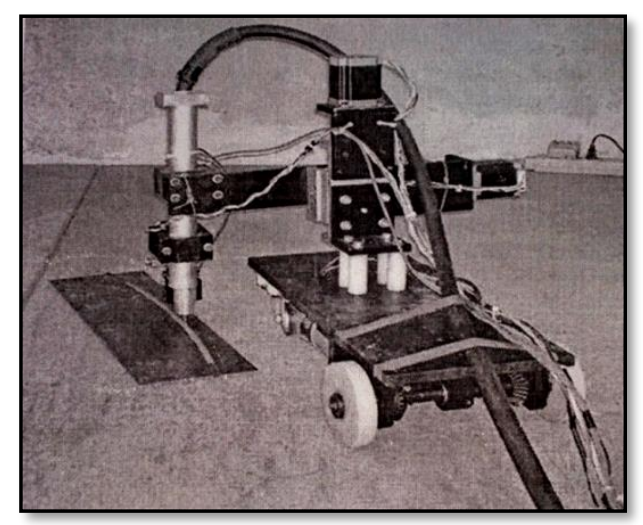

Figure 2: Existing Mobile Robot for Welding 


\section{- Proposed Mobile Robot}

In this proposed project, the motion of mobile robot is altered with Mecanum wheel control and ultrasonic sensor is used to do seam track [4] as shown in Figure 3. Since Mecanum wheel is used, the mobile robot can able to access 6 types of motion and allow the weld path to have a smooth motion. The merits of the proposed system are

- Improves precision of welding as seam tracking concept is used

- Able to do complex weld patterns irregular of its shape and structures

- Mecanum Wheels Provide slow and smooth motion which will move in any of the 6 configuration of movements (Diegel, et al., 2002)

- The proposed method can have no limits to work area and work space, such that the mobile robot can cover very large area

Initially, the robot is placed at the weld start point and it is actuated. The Ultrasonic Sensor mounted near the welding torch senses the seam to be welded and records the data [5]. The robot returns back to its initial point and starts welding. The welding is done based on the data points recorded by the Ultrasonic sensor. The horizontal and vertical motion is achieved by the Mecanum wheel and DC gear motor.

\section{COMPONENT SPECIFICATIONS}

The proposed mobile robot comprises of three major parts. First part consists of mechanical setup involving the chassis, Mecanum wheel, torch handle segment and aluminium mounting. Similarly, the second part is an electrical circuit which involves battery, driver integrated circuit board, ultrasonic sensor, switch, microcontroller and the third part have MIG welding system consists of electrode and torch [6]. The three parts work with synergy to perform the seam tracking using Mobile Robot. Once the input from the ultrasonic sensor is obtained and on checking the condition with microcontroller, the seam tracking process starts eventually. Table 3.1 shows the components mainly used in the system

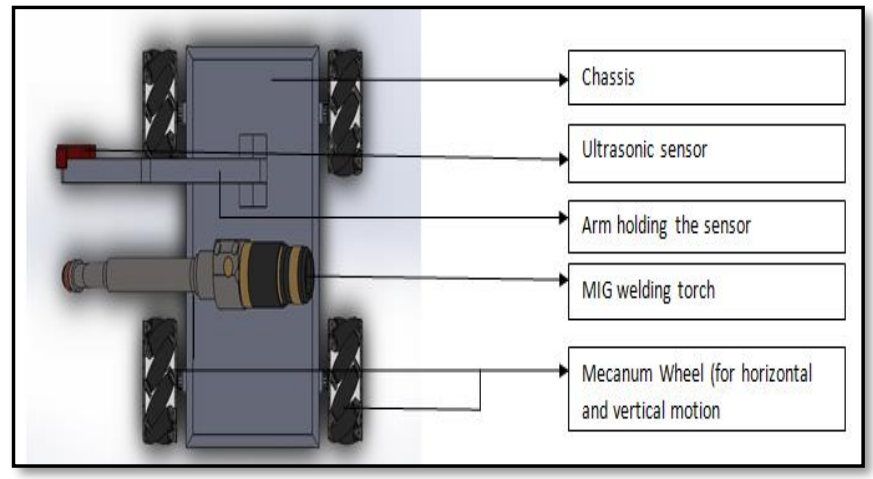

Figure 3: Proposed Model of Mecanum wheeled Mobile Robot for Welding 
Table 1: List of Components

\begin{tabular}{|l|l|}
\hline \multicolumn{1}{|c|}{ Components } & \multicolumn{1}{c|}{ Description } \\
\hline DC Gear Motor & $12 \mathrm{~V}, 20 \mathrm{kgcm}, 10 \mathrm{rpm}$ \\
\hline Micro controller & ATmega2560 \\
\hline DC Switch & For On and Off control \\
\hline $\begin{array}{l}\text { Mecanum } \\
\text { Wheel }\end{array}$ & To obtain desired motion \\
\hline Battery & Power for the microcontroller \\
\hline $\begin{array}{l}\text { Ultrasonic } \\
\text { Sensor }\end{array}$ & To achieve seam tracking \\
\hline $\begin{array}{l}\text { L298 Motor } \\
\text { Driver }\end{array}$ & For motor motion control \\
\hline Mild steel & Chassis design \\
\hline Buzzer & To denote obstacle avoidance \\
\hline Bolt and nuts & Low or medium carbon steel \\
\hline Coupling & $\begin{array}{l}\text { Connects the motor shaft to the } \\
\text { wheel }\end{array}$ \\
\hline U Clamp & To hold the torch \\
\hline
\end{tabular}

\section{Design Calculation}

- Mass of the components:

Material used

Density

Chassis

Motor mass

Battery

Welding Torch

Mecanum Wheel

Coupling

$$
\begin{array}{ll}
= & \text { Mild Steel } \\
= & 7.85 \times 10^{-6} \mathrm{Kg} / \mathrm{mm}^{3} \\
= & 3 \mathrm{Kg} \\
= & 0.4 \times 4=1.6 \mathrm{Kg} \\
= & 1.37 \mathrm{Kg} \\
= & 0.6 \mathrm{Kg} \\
= & 0.5 \times 4=2 \mathrm{Kg} \\
= & 0.2 \times 4=0.8 \mathrm{Kg}
\end{array}
$$

Total $\operatorname{mass}(W)=9.37 \mathrm{Kg} \sim 10 \mathrm{Kg}$

\section{- Motor Specification}

Motor Type : : DC Gear Motor

Torque of the motor $: 20 \mathrm{kgcm}$

Radius of the wheel $: 100 \mathrm{~mm}$ or $10 \mathrm{~cm}$

Therefore, Torque of each motor $=20 / 5=4 \mathrm{~kg}$

Total torque $=4 \times 4=16 \mathrm{~kg}$

Speed of the motor $=10 \mathrm{rpm}=0.167 \mathrm{rps}$

Distance travelled per revolution of wheel

$=2 \times$ pi $\times R=2 \times 3.14 \times 5=31.45 \mathrm{~cm}$

Distance travelled per minute $=31.45 \times 10=314.5 \mathrm{~cm}$

Velocity $\mathrm{v}=($ pi $\times \mathrm{D} \times \mathrm{N}) / 60$

$$
=(3.14 \times 0.1 \times 0.167) / 60=0.87 \mathrm{~mm} / \mathrm{s}
$$


- Microcontroller Specification

$\begin{array}{ll}\text { Manufacturer } & : \text { ATMEL } \\ \text { Model no } & : \text { ATmega2560 } \\ \text { Memory } & : 256 \mathrm{~KB} \text { (flash) } \\ \text { Digital I/O ports } & : 54 \\ \text { Analog inputs } & : 16 \\ \text { Crystal Oscillator } & : 16 \mathrm{MHz} \\ \text { RAM } & : 8 \mathrm{~KB} \\ \text { Timers } & : \text { Two } 8 \text { bit and Four 16bit timers }\end{array}$

- L298N Motor Driver IC Specification

$\begin{array}{ll}\text { No. of Motor Channels } & : 2 \\ \text { Maximum Operating voltage } & : 46 \text { V DC } \\ \text { Maximum Output Current / Channel } & : 2 \mathrm{~A} \\ \text { Minimum Logic Voltage } & : 5 \mathrm{~V} \\ \text { Maximum Logic Voltage } & : 7 \mathrm{~V}\end{array}$

- Ultrasonic Sensor Specification

$\begin{array}{ll}\text { Operating voltage } & : 5 \mathrm{~V} \mathrm{DC} \\ \text { Current Consumption } & : 15 \mathrm{~mA} \\ \text { Ultrasonic Frequency } & : 40 \mathrm{KHz} \\ \text { Maximal Range } & : 400 \mathrm{~cm} \\ \text { Minimal Range } & : 3 \mathrm{~cm}\end{array}$

\section{DEVELOPMENT OF MACANUM WHEELED MOBILE ROBOT FOR WELDING}

\section{CAD Modelling}

Designing is the most important stage of any product. The CAM tool SolidWorks is used to develop conceptual model of the Mecanum Wheeled Mobile Welding Robot. The reason for choosing SolidWorks over AutoCAD is the fact that the ease with working in the former one. At the outset, the part drawings are completed based on the specific dimension and the parts are assembled as shown in Figure 4 and its different views of 3D model of robot is shown in Figure 5.

\section{Electrical Interfacing}

The electrical circuit consists of Arduino AT Mega 2560 microcontroller, L298N Motor driver Circuit, Ultrasonic sensor and Lithium Ion Battery. Based on the values from the Ultrasonic sensor, the signals are fed to the Motor Driver, which converts these signals in the format required to actuate the motors. The electrical circuit for interfacing is shown in the Figure 6. The power source required for the operation of the motor is provided by the $12 \mathrm{v}$ and $4.5 \mathrm{Amph}$ battery. The motor are connected in parallel to the battery to maintain constant voltage and varying Current. 


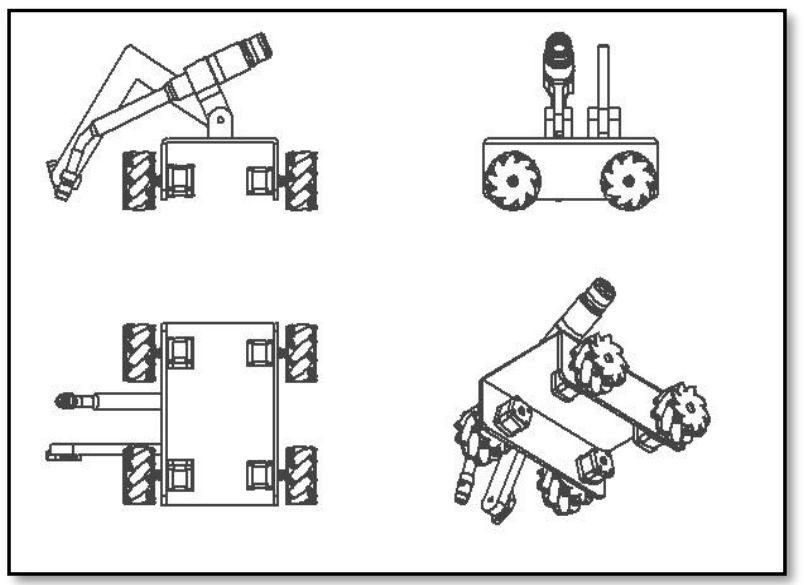

Figure 4: 2D Model of Mecanum Wheeled Mobile Robot

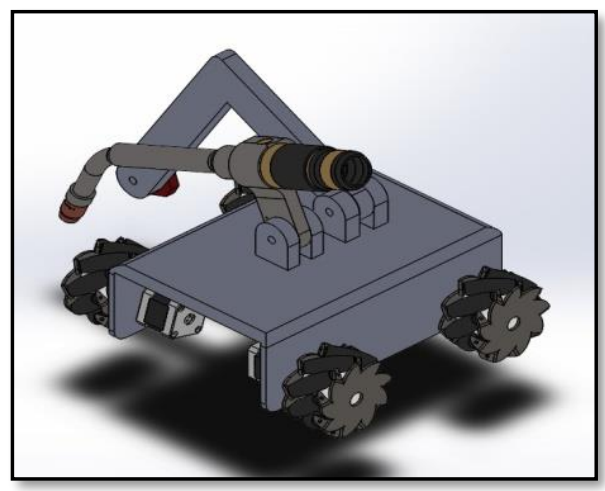

(5a) Isometric view

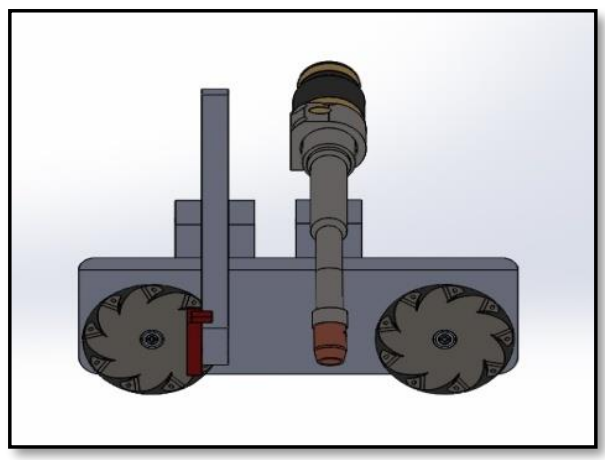

(5b) Left hand side view

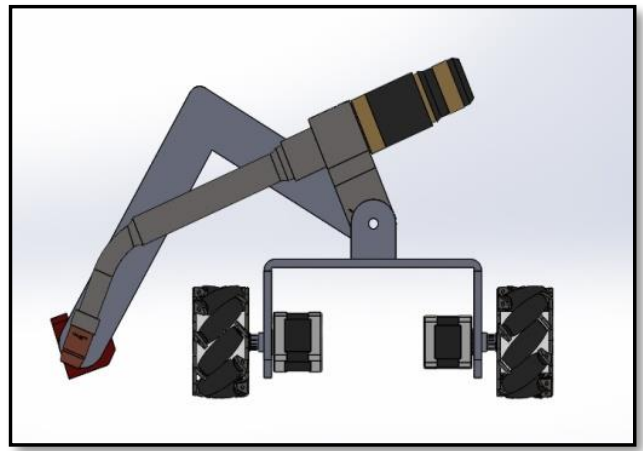

(5c) Front view

Figure 5: 3D Model of Mecanum Wheeled Mobile Robot 


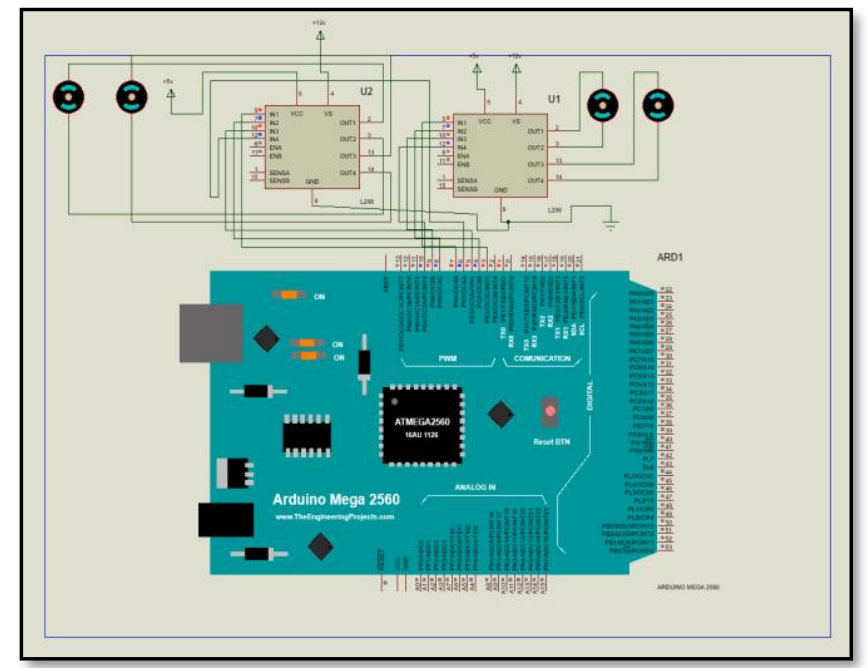

Figure 6: Electrical Circuit for Interfacing

\section{Fabricated model of Mecanum wheeled mobile robot for welding}

The mechanical section consists of frame or chassis which forms the base of the prototype on which the battery and electronics system can be placed. It consists of 4 wheels in total, 2 wheels in the front and two wheels at the rear, the axle of the wheels are attached to the chassis through bearings for smooth rotation of wheels, at the rear end. Gear motors of $20 \mathrm{kgcm}$ torque are used for carrying heavy load along with battery. Gear motor of 10rpm is selected, because slow speed is required for the welding operation. The wheels are attached to the motor with the help of coupling. The Aluminum coupling is used to reduce the weight. A separate holder is designed for holding the welding torch at the top of the chassis. The aluminum plate is projected from the side of chassis to hold the ultrasonic sensor which is used for sensing the seam to be welded. The complete fabricated Mecanum wheeled mobile robot is shown in Figure 7. In this, the electrical and the mechanical setup are arranged together such that the sensor senses the seam path, which then sends the signal to controller. Then, the motors get actuated and finally the motion of the robot is achieved with the help of Mecanum wheel.

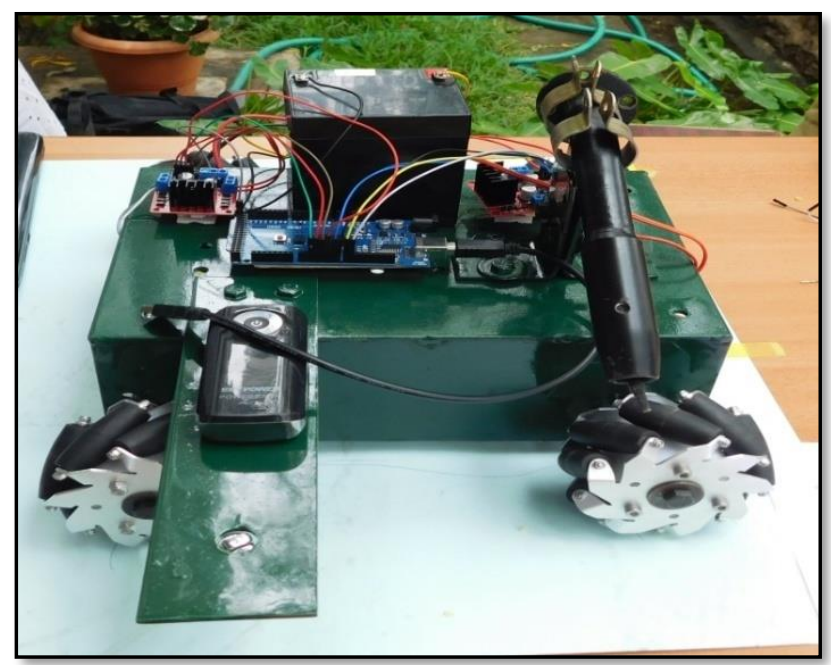

Figure 7: Photographic view of Mecanum Wheeled Mobile Robot for Welding

\section{CONCLUSIONS}

The Mecanum wheeled mobile robot was designed for the purpose of seam tracking in welding process. The metal body of the mobile robot helps to balance the weight of the arm. The welding torch is rigidly fixed on the clamp provided above the 
chassis. The sensor fixed to the arm senses the seam accurately and creates the required motion of the robot, with the help of the Mecanum Wheel and the control signals from the controller. This mobile welding robot reduces the need for the multiple robot and also has greater work volume than the normal robot whose base is fixed. Thus, this is an economical solution for the industry. By using this robot a long workpiece can be welded. By the use of Mecanum wheel, the robot can be moved both horizontally and vertically without changing its orientation, which results in proper welding. This robot can be further improved by incorporating Laser Displacement sensor and placing the manipulator over the chassis. Laser Displacement sensor will produce accurate seam tracking and the manipulator will help us to weld the work pieces which are of greater height.

\section{REFERENCES}

1. O. Diegel, A. Badve, G. Bright, J. Potgieter, and S. Tlale, "Improved mecanum wheel design for omni-directional robots", Australasian Conference on Robotics and Automation, Auckland, November 2002, pp.117-121.

2. T. S. Hong, M. Ghobakhloo, and W. Khaksar, "Robotic welding technology”, Comprehensive Materials Processing, vol.6, 2014, pp.77-99.

3. X. Lü, K. Zhang, and Y. Wu, "The seam position detection and tracking for the mobile welding robot" The International Journal of Advanced Manufacturing Technology, vol.88, no.(5-8), 2017, pp.2201-2210.

4. A. Mahajan, and F. Figueroa, "Intelligent seam tracking using ultrasonic sensors for robotic welding”, Robotica, vol.15, no.3, 1997, pp.275-281.

5. B. Maqueira, C. I. Umeagukwu, and J. Jarzynski, “Application of ultrasonic sensors to robotic seam tracking”, IEEE transactions on robotics and automation, vol.5, no.3, 1989, pp.337-344.

6. S. Hirose, and A. Morishima, "Design and control of a mobile robot with an articulated body", The International Journal of Robotics Research, vol.9, no.2, 1990, pp.99-114.

\section{AUTHORS PROFILE}

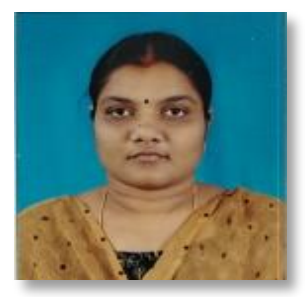

B. Meenakshipriya completed her Ph.D. in Proces Control from Anna University, Chennai (India) in 2012. Her active research areas include Nonlinear control, Process control, Robotics and control. She has published more than 90 articles in various journals and conference proceedings.

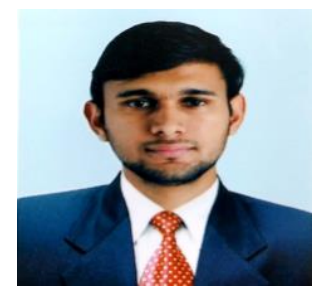

R.Anilkumar Choudary obtained his UG degree in Mechatronics Engineering. His area of research interest is Robotics and Automation. 


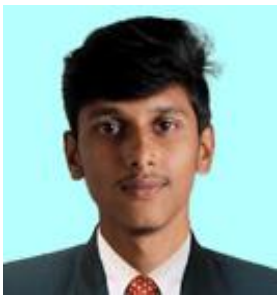

S.Deva Surya obtained his UG degree in Mechatronics Engineering. His area of research interest is Robotics and Automation.

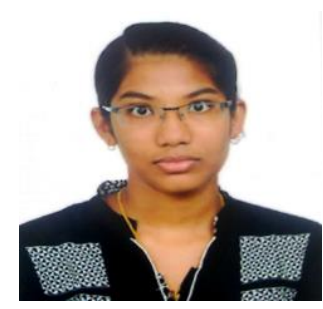

N.Subhashree currently pursuing her UG degree in Mechatronics Engineering. Her area of research interest is Robotics and Automation.

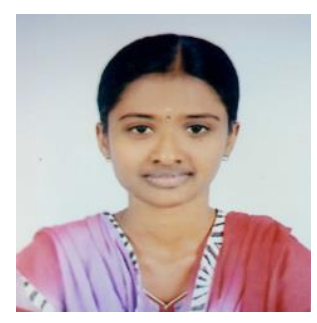

A.Prenitha currently pursuing her UG degree in Mechatronics Engineering. Her area of research interest is Robotics and Automation. 
